\title{
UNA NUEVA INTERPRETACION DE LA SEGUNDA SERRANILLA
}

Nuestras largats búsyuedas en los diversos fondos del Archivo de Aragón, relativas a la época de don Fernando $I$ de Aragón y su hijo Alfonso $\mathrm{V}$ el Magnánimo, nos han permitido ofrecer algunas identificaciones de poctas áulicos de esta ́́poca, como puede verse en nuestra edición del Cancionero de Palacio, enriqueciendo o perfilando los datos biográficos de los mismos; también creemos nos pueden facilitar el mejor conocimiento de algunas poesías de esa ćpocal, cumarcíndolas dentro de su ambicnte político, histórico y social. Un ejemplo de ello es la nueva interpretación que damos a la segunda serranilla. del marqués de Santillana.

Esta serranilla se encuentra en el ms. VII, Y, 4 . (olim 1114) de la Biblioteca de Palacio (Madrid) y en el ms. M, 59 de la Biblioteca Nacional (Madrid); ha sido publicada por Amador de los Ríos y modernamente por García de Diego '. He aquí su lectura:

En toda la su montanna

de Trasmoz a Veraton

non vi tan gentil serrana.
Partiendo de Conejares, alla susso en la montanna cerca de la Travesanna,

1 AMMDor n: los Kíus, Obras de don lñigo López de Mendozar marqués de Santillana. Madrid, 1852, y Gakcí de Diego, Marqués deSamillana, Canciones y decires. Col. "Clásicos Castellanos", volumen XV'lll. Madrid, 1913. 
camino de lrasovarcs,
cncontre moşa loçana,
poco mas aca de Amnon
riberas de una fontana.
Traia saya apretacla
muy bien pressa cn la cintura,
a guissa d'lestremadura,
cinta c collera labrada.
Dixe: "Dios te salie, hermana; aunque vengas d'Aragon, desta scras castcllana." Respondiome: "Cavallero, non pensses yute me tencics. cit primero provaredes este mi dardo pedrero; ca despues desta semana fago boxlas con Anton, vaçueriyo de Morana?.

Dentro del cañamazo ya estereotipado de las serranillas, ésta nos ofrece. como casi todas. la gracia traviesa de la scrana, pero dqué falta aquí de la auténtica gracia de la vaqueira de la Finojosa?. ¿qué avaricia de vivencia cn el encuentro serrano? y por más contraste. ¿qué abundancia de citas geográficas? Cono si el centro de atracción del alutor no fucra un lance amoroso, sino el recuerdo de un largo y extmano viaje a través de un itinerario complicado que va descle los aledaños de Agreda, cn Castilla, rodeando el Moncayo. hasta las planicies de Zaragoza. Como decimos, el marqués. con ahincada porfía. nos. da una seric de detalles geográficos. complicados y diversos, que han de ser indiferentes y cxcéntricos a una aventura scrrana. Desde lucgo, es una escenografía larga y complicarla que cxcede cl marco corriente de una atventura amorosa.

Además. es chocante que al requerir el autor a la serrana aragonesal, esperando que va a abandonarse en sus manos para ser castcllana, ésta responda, ya no de modo. arisco y abrupto, sino con la amenaza de lanzar su "dardo. pedrero", y que después de una semana haga "bodas con Antón, vaquerizo de Morana". ¿Qué se esconde tras tan elípticas alusioncs? ¿Es que cse verso final, "fago bodas con Antón", sólo se ha escrito para encontrar consonante. con "Annon" y "Aragón?

2 Crcemos que la Scrranilla 1.2, "Serranillas de Moncayo", no cs. ajena al ambiente $y$ asunto de esta que es objcto de nuestro estudio, pero la clejaremos para otra ocasión. 
La inventiva tam fácil del marqués no tenía por qué acudir a cstos extremos para tejer sus rimas. Y lo mismo diríamos de su tan circunstanciada topografía: de Trasmoz a Veratón, o bien de Conejares a Trasovares, "mas aca de Annon", cerca de la fortaleza sanjuanista de Añón. Estos nombres marcan cl paso de la frontera aragonesa en las dos direcciones de salida del reino aragonés.

dis que toda esa topografía, tan prolija y circunstanciada, le era precisa como marco de un simple encuentro amoroso? ¿No había otro designio? Máxime si tenemos en cuenta que Trasovares no cra en el siglo xv casi otra cosa que un gran monastcrio de religiosas del Císter. ¿Ls posible que todas estas referencias personales sean un mundo de pura imaginación del pocta, que lo mancja como un mundo de marionetas? Ya hemos dicho que la atención del autor parece más centrada en estos detalles colaterales que en la emoción psicológica del encuentro. Siendo así. ¿cuál podría ser la verdadera significación de la scrranilla? Despućs de haberlo meditado mucho, creemos que no es improbable una interpretación histórica, y en parte politica, de esta breve serranilla. con la cual toma un carácter afín al más intencionado sirventés.

Todo csto nos invita a crecr que esa "tan gentil serrana" y "moça loçana" que encuentra Iñigo López de Mendoza en el Somontano y camino de Trasovares, la cual no quiso ser castellana, pues pasada una semana debía "fazer bodas" con "Anton vaqucrizo de Morana", no es ni más ni menos que doña Violante o Brianda de Luna ${ }^{3}$, abadesa nada cjemplar que fuć del monasterio de religiosas cistercienses de la villa de Trasovares y cnvuelta en unos amores escandalosos con su primo Antón de Luna.

Dama aragonesa altiva y voluntariosa que, disconforme en apariencia con la decisión de Caspe, en realidad con la herencia del condado de Luna por don Fadrique

a Vid. Zukima, Anale's de drayón, vol. III, fol. 13, col. 1 (año 2+10). y también Linajes de Aragón, vols. I-Il. 
de Aragón, hijo natural de don Martín de Sicilia t, no - dudó en linzarse en brazos de lia revuclta política aragonesia y seguir el partido de su pariente don Antón de Luna, uno de los cómplices del asesinato del arzobispo de Zaragoza. don García Fernández de Heredia ${ }^{5}$, sccuaz y portalestandarte de la rebelión de Jaime de Urgel contra Fernando de Antequera, I de Aragón-después de la resolución de Cáspe-. que terminó con la desgraciada resistencia en balaguer. Don Antón y demás cómplices del asesinato del arzobispo, puestos en entredicho eclesiástico por Benerlicto XIII y confiscados sus bienes, vislumbran una esperanzal de posible rehabilitación apoyando $c$ instigando la rebelión del desgraciado conde, abandonado en la desgracia por sus propios partidarios.

No intentamos, ni inucho menos, historiar las luchas - elel conde de Urgel, delicada y extensa labor ajena a cstas páginas. Tampoco intentamos agotar la biografía de la abardesa de Trasovares y don Antón de Luna, y si sólo apuntar la presencia activa del autor $y^{\prime}$ los dos intérpretes de la scrmilla en la política del breve y activo reinado del rey don Fernando I de Aragón ".

No olvidemes que don lñigo López de Mendoza vino a Aragón con el sécquito del rey don liernando; desempeñó en la casa del primogénito, el infante don Alfonso, cl cargo de copcro mayor. Siguió activamente todos los hechos de armas en la lucha con el conde de Urgel; estuvo en el sitio de Balaguer y descmpeño misiones deli- Cadas en nombre del rey cerca del conde de Cardona',

I Nicto, por lanto, de la reina Maria de Iuna, de la cual habia herediadn su pautre el condado de Luna, que le transmitió en herencia. fil rey don Martin instruyó proceso de legitinación de su nicto para darle poscsion del condado de I.una.

Al venir al trono de Aragón, Fernando de Antequera tomó a su cargo y custodia al conde ion Fadrique, respetanclole y guardaindole : sus leurios y scinorios.

$\therefore$ Vicl. Zimim, loc. cil. III, fols. i2 sigs.

: Años $1+12-1+16$.

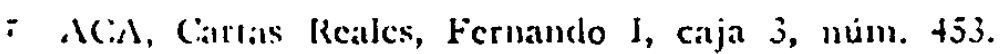


del primogénito, de la reina. Sus idas y venidas de Castilla le facilitaron el práctico conocimiento de las zonas. fronterizas y de los pasos, más o menos frecuentados; la guerra le familiarizó con los campos y lugares de combate, castillos tomados por sorpresa y rescatados, intrigas. de la abadesa, estratagemas de don Antón de Luna.

Trabado conocimiento con los personajes y las actividades político-nilitares del autor, realicemos una imaginaria expeclición por las estribaciones y contrafuertes del Moncayo hacia los llanos de Zaragoza. Seguimos el itinerario apuntado por el marqués "de Trasmoz a Veraton", o sea, el paso de la frontera en dirección hacia Agreda y camino de Navarra: el castillo de Trasmoz, a unas 16 leguas de Zaragozal, está situado en una cminente colina que domina lejana extensión; no cstá lejos del monte La Mata, al pie del Moncayo ${ }^{8}$; hoy día es: “... aquella fortaleza que. según conscjas de brujas, levantó el diablo en una noche..., tosco castillo desamparado que ruega al tiempo demora en su total desaparición. Es una fortaleza de planta circular, torres rectangulares y cerco unido y simple que rodea cl Homenaje, cuyos cimientos senalan haber sido en sus principios una posición defensiva del cursus de la calzalda romana que serpentcaba por las cercanías" ". Estaba esta fortalcza en manos de los Ximénez de Urrea, durante el reinado de Fernando I de Aragón, representada esta familia por don Pedro Ximénez de Urrea.

Beratón es un lugar fronterizo con Aragón, perteneciente a la provincia de Soria, a unas 10 leguas de la capital; tenia varios caminos de herradura, de los cuales. uno la comunicaba con Agreda y otro se dirigía hacia el

s Vid. Misroz, Diccionario Cicográfico, vol. XV, núm. 134. Тr:kk:ros, Paisajes y pastoras en las "Serranillas" del marqués de Santillana, c1 Cundernos de I.iterutura, vols. VII-VIII (1949-50), págs. 169-202.

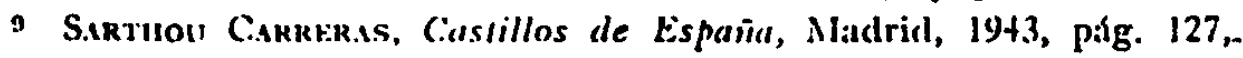
nimero 117. 
castillo de Añón, en la provincia actual de Zaragoza ${ }^{10}$. "Pertenece al partido de Agreda y se halla junto a la frontera de Aragón, al sur del Moncayo y al norte de Sicra Tablato, en la cuenca superior del rio Araviana, subafluente del Duero" ".

Particndo de Concjares, caserio de la provincia de Soria, en el municipio de Muros de Agreda, está situado al pie de una colina. "abierta a los cicrzos". Tenía una capilla dedicalda a la Virgen de las Nicves. Al sudeste de Agreda, está sobre la carretera que la une con Soria, en cl camino de Madrid a Navarra ${ }^{1 "}$.

Cerca de La Travesana, "nombre desaparecido, que lo mismo puede ser un puerto o la traresía” ${ }^{13}$. ¿También podría signilicar la misma frontera?

Camino de: Trasovares, villa que pertence a la provincia, diócesis y audiencia de Zaragozal, en el partido de Borja; a unas 13 leguas de la capital. enclavada en una honclonada por terrenos muy montañosos, en tiempos antiguos pobladísimos de pinares y encinas, pero huérfanos de arbolado descle los primeros años del siglo pasado ${ }^{14}$. Dice Madoz que seguía abierta al culto la iglesia del "Monaslerio de religiosas cisterciense's, bajo la advocación de Nuestra Sciñora de la Piedad".

Poco mis ací de Añon. Próximo a la frontera de Aragón y Castilla - hoy división provincial con Soria-, en la región descrita por el marqués, sc yerguc el castillo de Añón "en aguileña altura de las rugosidades serranas" ${ }^{15}$. Pertenecía a los caballeros de San Juan de Jerusalén y era la sede del comendador de Añón. Situado a unas 11 le-

10 Vid. Sinmoli, loc. cit. MADoz, loc. cit., vol. IV, paig. 235.

11 Vici. Térkinos, loc. cil., pág. 1it.

1.2 Vid. Mladoz, VI, 561. Terreros, loc. cil., píg. 174.

13 Vid. Thakeros, loc. cit., pág. 1it.

1.t Vid. Manoz, loc. cit., rol. XV, pág. Ijt, y Terkeros, loc. cit., página 174.

15 Añón, Castillo de. Vicl. Sarthoc, loc. cit, pág. 125. Terreros, loc. cit., págs. 174-75, y Fedrerco Berdr:jé, Rulas becquerianas, en Rcvisla de Aragón, núm. 74, año 1931. 
guas de "Zaragoza, por la falda meridional del Moncayo, tiene a sus pies desparramado el pueblo del mismo nombre, y sus términes lindan con los de Beratón, en la provincia de Soria "i.

La "Moça loçana", que se cruza en la ruta del marqués, con su indumentaria "a guisa de Extremadura", la región llamada Extrema Durii, o sea, la cabecera del Due-. ro en los principios de la reconquista ${ }^{17}$, denominación que no es difícil perdurara aún en el siglo xv.

El encuentro no es idílico; la serrana, que lleva" cinta e collera labrada", signo tal vez de distinción, no oye palabras de amor del marqués ni la dulzura de un requiebro; auncuue de estirpe aragonesa, ha de caler en manos de los castellanos. I a reacción es aún más ariscal y en son de guerra: "Non pensses que me tenedes": antes me resistiré por todos los medios y con armas de guerra. "Ca primero provaredes -este mi dardo pedrcro." Pues va a desposarse con Aulón, -vaquerizo de Morana. El barranco de Morana comunica Añón con Beratón a través de la montaña, y es el paso de los ganados al trashumar de Zaragoza a Soria "s. Puede muy bien imaginar el marqués a este afortunado rival con sus ganados derramados por ese barranco; pasando tal vez su oveja clescarriada de Aragón hacia Agreda, camino de Navarra.

El panorama político del reino aragonés a la mucrte del rey don Martín el Ilumano era complicado y caótico, y a la sombra de los pretendientes se intentaba liquidar bandosidades familiares intentando subordinar los intereses del reino a muchos $\mathrm{y}$ variados intereses particulares.

Verídico y documentado cronista, Jerónimo de Zurita, nos habla de los disturbios y disensiones que prece-

\footnotetext{
16 Mino\%, loce cit., vol. II, prig. 355.

i: Tharkinos, loc. cil., 176.

is Tekrtinos, loc. cil., pigy. 17\%. También habla de estos lugares v los describe Bécyuer en sus cartils escritas descle el Monasterio de verucla.
} 
dicron a la lucha y sublevación de Jainne de Urgel. Nos presenta la situación de cion Antón de Luna el año 1412 , despućs del ascsinato del ar\%obispo de Zaragoza, don García fernándé de liferedia ". en estus términos: “... como don Antonio de Luma se vió fuera de su estado, que era. grande, y se comenzaba a repartir entre sus cnemigos, ponía al conde de Urgel en la guerra que o todos se perdiesen, o sucediendo prósperamente las cosas, se acrecentasen sus casas: y di pretendía suceder en el cstado, que fué de :lon.Pedro de Exerica. su abuelo, que fuć un gran senor de la casa real: y turo muchas villas y castillos, que halían vuclto a la corona o se habian cnajenado: y por csta causa se començo al llamar don Antonio de Luna y de Excrica..." :".

Don Antón de Lana incitó constamemente al conde de Urgel a la relselión. ayudado por la madre del conde, Margarita de Monferrato. Superaron ambos las vacilaciones del conde, que siguió sus consejos, terminando sus días en prolongada y triste peregrinación por las prisiones de los castillos de Ureña. Castro-Torafe y Játiva.

Fl alférez mayor del reino, que llevó el estandarte real cn la coronación del rey don Martín, que despucis fuć su camarlengo y pertencció a su Conscjo. cra don Antón de Tuma, scũor del castillo de Loarre y aliado del conde de Urgel en las handosidades que hubo en Aragón durante la lugartencncia del conde, desempeñada con más o menos acicrto. A don Antón de Luna tuvo que amonestar la rcina doña María de Luna a causa de las vejaciones

1: Wil hecho suceclio en el camino de la Almunia de Doña Godina el día 1 de junio de 1+11. Vid. Cosme B1..ssco, Historia de Zaragoza.

-n Este abuclo scria Pedro Martínez de Juna, casaclo con Elfa de Xerica; que vivió en la primera mitad del siglo xis. V'id. Greconio García Cipris. Los L.ma, en tinajes de Ararón, rols. I-II, 1910-11, priginas 145 sigs., Zurax, loc. cil., vol. 11I, fol. 79, 1412, de donde está tomiado csic pasaijc. 
infligiclas por la gente dẹ conde a los juclios de la Aljama de lexen $" 1$.

Después del trágico suceso de La Almunia de Doña Godina andaba don Ạntón huído, en entredicho religioso; desposeido de sus bienes, se parapetó en su fuerte castillo de Loarre, y no tardó en verse asediado por el gobernador de Aragón, don Gil Ruiz de Liori, secundado por don Juan Fernández de Heredia, sobrino del arzobispo asesinado; don Pedro Ximénez de Urrea, enemistado por motivos muy personales y familiares con los Cornel de I una, y por don Juan Fernández de Bardagí. Recibió el sitiado don Antón de Iuna pronto auxilio de las gentes del conde de Urgel, contrarrestado por las compañias del infante don liemando de Antequerai. que vinicron en allxilio de los sitiadores.

La toma, casi por sorpresa, del castillo de Trasmoz, el 8 de mayo de 1413, siguiendo el clía 11 del mismo mes la toma del castillo de Montearagón nor los hombres de don Antón de Luna, fué el chispazo que prendió la reguera de pólvora de la rebelión. El conde de Urgel ya no pudo retroceder. se fortilicó para resistir, en Balaguer, mientras don Antón de Luna mendigaba auxilio de hombres de a pie y de a caballo por las cortes de allende los Pirineos.

El genealogista de los Luna, Gregorio García Ciprés, dice que don Antón de Luna, al ver el giro adverso de la campaña de Balaguer. huyó a Francia y expone en los siguientes términos los hechos posteriores que nos interesan: "... dejando la defensa de Loarre a su hermana doña Violante de Luna, abadesa de Trasovares".

"Tomado Balaguer (1-XI-1413) fué trasladaclo todo el tren de guerra a Loarre, apretando el cerco que la había puesto su enemigo don Pedro de Urrea. Pusiéronse en juego grandes influencias para libertar a doña Violante,

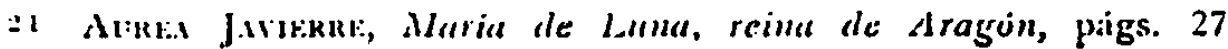
. 253. 
interviniendo el P'ontífice, don l'edro Martínez de Luna, su paricnte, y hatsta el mismo rey" $=2$.

"A Jos ocho meses de formidable asedio se rindió dona Violante, entregando el castillo a las tropas reales, quedando prisionera de don P’edro de Urreal después fué traslaclada al castillo de Sorá, bajo custodia de don Pardo de la Casta. l'uesta al lin en libertad dona Violante, se juntó en Francia con su hormano, ignorándose su póstumat strerte" a:.

Siguiendo has huellas del citado genealogista. señor Garcia Ciprés - hemos de destacar que no esta muy clara la liliación de den Antón de lama--, veremos que en el sigho xiv don lape de lanal, señor de. Segorbe, dejó la Unión y siguiei al rey. peleando en la batalla de bipila en las lilas de Pedro IV. Este dom Lope de I, ma, señor de Segorbe, tuvo cuatro hijos: don Juan Fernandez de Luna - que murió en la lacha contra el rey Jaime de Mallorea-, sin sucesion, y pasaron sus derechos a su hermano. don Lope lermández de Luma, arzobispo de Zaragoza, el cual, en mayo de 1382, hizo testamento a faror de su hermatna, doña Toda Fernande\% de I,una, casada con don Ximeno de Urrear. y si no tenía descendencia legítima. sustibuyendo don Alibin de Luna, su sobrino. ¿Cómo podía ser don Antón de I ana su sobrino: Sigamos revisando el cladro gencalógico y encontraremos otra hermana del ar\%obispo. Hamada doña María Fermández de Luna, casadal con don Pedro, señor de Ayerbe ": Nos inclinamos a creer que éstos podrían ser tal vez. los padres de don Antón, máxime si tenemos en cuenta que Aycrbe fué el contro estratégico de muchas de las fechorías de don Antón de Lumal.

Más difícil será, tal vez, adivinar la ascendencia de doña Violante de Luna, la belicosa abadesa de Trasova-

2.2 Vial. Jimajes de dragon, vols. I-II, jags. 2ti signs.

2.3 Vid. nota anterior.

$\because 1$ Vill. Limajes de Aragrin, vols. I-Il. pigs. 192 y sigs. Don Lope Pimsines de Urrea fué el primer virconele de Rueda. 
res. Vamos siguiendo las genealogías de las diversas ramas de los Luma ${ }^{25}$. y la reina, María de Luna, esposa de don Martin el Humano, hija de don Lope Ferrench de Luna - casado dos veces ${ }^{26}$-, tenía un hermano llamador don Artal de Luna, casado en Sicilia con Margarita de Peralta, condesa de Caratabelota, y una hermana, doña Brianda de Luna, esposa de don Lope Ximénez de Urrea, del cual se separó, y despućs de cuatro años, a instancias. de sus familiares y de algún eclesiástico, volvió a unirsecon su esposo, don Lope Ximénez de Urrea, para huir a los pocos días con don I uis Cornel, señor de Aljafarín, residiendo juntos largo tiempo en dicho lugar. Finalizaron estos devaneos con el destierro de don Luis Comel. Doña Brianda, por intercesión de lat reina su hermana, puclo retirarse a terminar sus días col un monasterio. $Y$. originaron estos desatinados amores las largas bandosidades entre Corneles y Urreas.

Señala Zurita a este don Luis Cornel como padre de la abadesa de Trasovares, doña Brianda de Luna, pues, hablando de los pretendientes a la Corona de Aragón en el compromiso de Caspe, asume las aspiraciones de los Luna con estas palabras: "Don Fadrique de Aragón, en su menor edad, estaba tan si favor, muerto el rey de Aragón su abuelo, que no tuvo poco que hacer en entrar en la posesión del estado, que fué del rey de Sicilia su padre; por el derecho que otros pretendian en él, por el testamento del conde don Lope de Luma su bisabuclo: señaladia. mente doña Brianda Cornel, hija y heredera de don Luis. Cornel, que era nieta del conde don Lope" ${ }^{27}$. Eran éstos Cornel de luna, y podríamos suponer que Brianda Cor-

25 En todo to que hace referencia a los linajes nos atenemos al estudio genealógico de la familiat hecho por G. García Ciprés y publicado en Linuje's de itraroin, vols. I-II.

$\because$ Vid. loce cit., Linuje's de Aragoin, I-II, págs. 65 y sigs.

-i los luna esturicton emparentados con los Cornel y fué la rama de los cornel de l.mat. V'id. Zurra, Aluales, III, fol. 13. Vid. Linerjes de . Irasint, prig. cit. 
nel es la misma Brianda de Luma, nicta, por tanto. del conde don lope de luna. No queremos suponer para esta abadesa una triste bastardía, fruto de los adúlteros amores de don Iuis Corncl con la esposa de don Lope Ximéncz de Urrea, doña Brianda de Isma"s.

No creemos, pues. que la abadesa de Trasovares, doña Brianda de Luna. fuera hermana de don Antón de Isuna. como dice García Ciprés ${ }^{29}$, sino primos en segundo o tercer grado. De no ser así, ¿cuán terrible no habría sido la actitud audiz y rebelde de ambos, piedra de escánclalo cn redo el reino de Aragón?

Desencadenatdas las bandosidades de Aragón so pretexus de la relelion del conde de Urgel. parece ser que la abaclesa aprovechi la coyuntura para dejar la par de su monasterio, trasladíndose a las montanas de Jaca, y, a la vera de don Antón de Luna, resistir en el castillo de Loarre, scñorío del mismo.

Una carta dirigida por el rey don Fernando - clesde el sitio de Balaguer (4 octubre 1413)- al rey de Navarra, suplicándole mande prender secretamente a don Antón de Luna. que se ha refugiado en un castillo de Navarra. está concebida en los siguientes términos:

"Rey muyt caro c muyt amato tio. Nos cl Rey d'Aragon vos enviamos muyto a saludar como aquell por a quicn querianos tanta salut, hoinra e bonaventura quanta vos nismo descarles e por nos mismo descamos e jor quien farcmos todas cosas de buena rolundat. Rey muy caro e muy anado tio: Bicn saluedes quantos son los. cscandalos, quantos los malvados actos e otros crimenes, sediciones e mucrtes que suthon de l.una a nos rebclle ha perpetrado, suscita(b) e attemptido cn nuestros regnos e terres c cuerpo, contra nuestra Magestat e persona propia de que no solament ros mes nos e todos. los qui amen nuestra honor deben procurar rigoroso castigo juxta la inormiclat de tan granics excessos; por que Rey muyt caro c nuyt amado: Nos como havamos entendicio quel (ito Anthon de Luma ste. ce un castillo vuestro o de rucstro regno chamaclo Uquar ros rogamos assin affcctuosamcnt c coral como podemos que aqucll mandedes se-

28 Llermana de la reina Maria de Juma.

29 Loce cil., pilgs. 247 y sigs. 


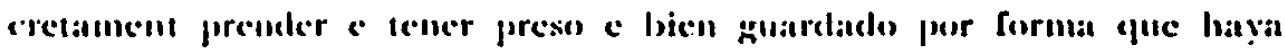
l: punicion yue sus demeritos exhigexen; offerientes vos que ness en semblant eatso, loxplatul falllo ruestra honor e buen stannicuto de los nuestros en dicerses maneres perturbaclos por el dito Anthon, assimisno' lo mandariamoss executar. E de todas otras cosas que podamos fazer por vos nos serivit fiablement li haya vos Rey muy caro e muy amado tio el sancto spirito en ruestra continua protection e guarcla..." 3".

Esta carta, decimos, nos permite suponer que, próximo a rendirse Balaguer ${ }^{31}$, vió Antón de Luna que su suerte estaba echada: abandonó Loarre, atravesando secretamente las montañas, y fuć a refugiarse en el reino de Navarra al amparo de algún pariente o amigo. Dos díns antes de la lecha de esta carta, había saliclo, a uña de caballo. de l3arcelona lñigo lúpec de Mendozal Ilevando una carta del primogénito para el conde de Cardona, en la que le rucga atienda cuanto le diga don Iñigo de su parte y lo ponga por obra: sale el marqués de Cervera el día 4 de octubre llevando una credencial del rey también para el conde de Cardona "2", con la misma fecha de la carta al rey de Navarra -4 de octubre-, reclamando a don Antón de Luma. No estaría muy ajeno don Iñigo a la búsqueda de don Antón.

Loarre. escenario de belicosos amores, queda el último baluarte rebelde ${ }^{3:}$. Tras varios meses de asedio se rindió

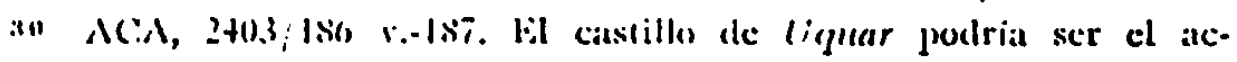
Iual castillo de cljue.

31 lil rey don Fernatndo. en cartat fechada el 31 de octubre de 1H13, anuncia a los Pahers de I.cirida la rendición de lbalaguer.

3: ACA, Cartas Reales Diplomaticas, Fermando I, caja 3, número +53 .

$33 \mathrm{ACA}, 2+03 / 137$ r.-137

-El Rey:

Léricla, 11-novicmbre-1413.

Don Pedro vuestra letra bavemos recebido, e acquella entendida respondemos vos que pues los de aquexe castillo de Loarre assin como a rebelles a nos persereran en su pertinacia dampnada de rebellion, queremos el dito cistillo, e todos aquellos que dentro aquell son, 
a los soldaclos del rey y quedó la abadesa en poder de don Pedro de Urrea, que la guardaría seguramente en su fortalcza de Trasmoz, no lejos de Trasovares. Seguramente don Antón de Luma estabat yal lejos de Loarre, pues no hemos encontrado ninguna referencia a que hubiese caído en manos de los sitiadores; lo que si hemos encontrado son referencias y documentos solre la voluntaria entrega de don Antón, dispuesto a cumplir cuanto se le ordence a condición de salvar a la abadesa y que sea "scgura de vida. presion e mutilación".

Intentemos ahora esbozar el desenlace de csta norela vivida en los albores del siglo $\mathrm{x} v$ y reladamente condensada por don Inigo López de Mencloza en una movida y desembarazada Serranilla.

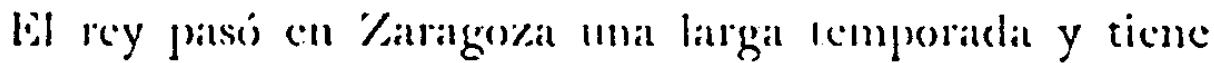
la preocupación de acabat a buen recaudo el asunto de la albadesal de Tratsovates, mujer de roluntad firme, difícil de doblegar. Trató el asunto con don Pedro de Urrea, y para poner en práctical lo que habla "sobrel feyto de la abadesa" le manda una orden por Pedro Companyó. secretario del primogénito. diciéndole que deben ir a parlamentar con la abadesa cicrtas personas, y para cllo deberá cntregarla al merino de Zaragoza (Pardo de La Casta), bajo juramento de devolverla terminadas las entrevistas. El merino deberá custodiar a la abadesa en cl castillo de Sorá "passaclo ruit dias dentro los quales la dita faula sera feytia le restimyra la dita Abbadesa de liure en la

haver con mano fuert a nuestra mano. Por que vos enviamos de present dos engenyos c dos bombardas grossas, e cient atclalieles; por tal yue los estrengaties e vexceles en ha mancra que se pertencece haviendo vos en aquestas cosas segund que de ros lirmement confiamos, si nos deseades servir e complazer. Rescriviendonos continuament de todas aquellas cosis que sc succehiran. Dada en l.crida dius nuestro siello secreto a Xi dias de Noeconbre del an!o Mo C.C.CCo Xul. Rex Ferclinandus.-Gabricl Mascaroni, mandato regio facto ad relacionem Didaci ferdinancli de Vacdicllo, Secretarii.-Provisum."

Va la carta dirigida a don pectro de Urrea, que cra en aquellos momentos el sitiatlor de loarre. 
forma que sera aconmodada e sin algun impediment" ${ }^{34}$. Al mes de expedida la orden de traslado de la abadesa, escrilic el rey a la misma (Zaragozal. 19 mayo 1414), comunicándole que recilirá la visita de dos venerables eclesiásticos: el obispo de Scgovia y fray Diego de Támara, confesor del rey is.

El 20 de mayo expide el rey la orden al merino de Zaragoza para que los citados eclesiásticos puedan entrar en la

is ACA, 240t;itis.

Zaragoza, 22-abril-1+14.

$"=$ J als cosas dejuso scriptas explicara en Perc Companyo al Noble bon lediro Durrea, por vigor de unn letra de creyenca que sen lievat del Senyor Rey:

= Primerumint çue como el dit! Senyor quiera cnviar algunas personas cyue latulen, de su piart, con la Albadesa de lirasovares, que Jo rucga! que la dita Abbactesa liure o faga liurar en porter del Mcrino el cunl tendra açuclla en el castiello de Sora, por el o por aquel. qui la li liurara; a do el dito Senyor chviara aquellos que ordenara que faulen con la dita Abladessa. Paulus, Secretarius.

= Item que antes que la dita Abbaclessa sca liurada al dito Mc. rino, el clito Mlerino fara sagrament $c$ homenatge al dito don Pedro yue passados ruit dias dentro los quales la dita faula scra feyta, le restituyra la dita Abbadessa de liure en la lorma que sera aconmadacla $c$ sin algun impedinent. Rex Ferdinandus.-Dominus Rex mandavit mihi Paulo Nicholay."

3.5 $A C A, 2+0 t / 56$. El obispo de Segoria cra clon Juan Vaizquez. de Acebedo (o Cebeclo), arcediano de Scvilla, elevado a obispo de Scgovia en 17-V1-1.3\%, hasta 1436. Funfi, Mierarchin Cat., J, 445.

"lil Rey:

Vencrable Abbaclessa: Sobre algunas cosas las quales de muestra part vos diran los venerable Padre en Christo, consclleros amados nuestros en... l3isle de Segovia et lisay Diago de Tanara, mucstro confessor, havenos los ditos nuestros conselleros plenament informados de nuestra intencio porque vos rogamos que dando fe c crelıença it todo lo yue los sobreditos vos diran de part nuestra, aquello complades por obra si nos deseades complazer e servir. Dada en Chíragọ:a dius nucstro sicllo secreto a XVIIII dias de Mayo del anyo Mil Quatrozicntos Quatorze." 
cámara de la abadesa, en el castillo, y hablar con ella cuantass veces bo crean necesario ${ }^{36}$.

También fue a los pocos dias al castillo de Sorai. paral hablar con la abadesa. el notario Ximeno de Odina, al cual, con fechat 2 de junio de 1414, le cxpide cl rey la correspondiente orden y permiso de cutrada en el castillo, y para que le permitan hablar con la abadesa de Trasovares cuantas veces crea necesario, dirigida a mosén Pardo de la Casta, merino de Zaragoza, y a Juan de Lixar, escudero, "tenientes del castillo de Sorá" 3 .

De todas cstas gestiones se da cuenta al Pontífice Benedicto XIll por Suero Alfonso de Sorís, caballero cnviado por el rey a Su Santidad para tratar de "quibusdam factis sive negrociis Abatisse de Tresorares", con credencial de 8 de junio de 1+14. expediela cn Zaraguza ${ }^{38}$. De lo que se trató en esta Misión, llevada por Suero Allonso de

:) $\Lambda(: \Lambda, 2+04$.

"Mlerino: Vos enviamos anui los venerables ladre en Christo e Consclleros nucstros Bispe de Segovia e nucstro conffessor, por faular con la $\Lambda$ baclessa de Tresovates ciertas cosas de nucstra part, por que ros mandamos que a los ditos nuestros Consclleros, c aquellos que con cllos iran. lexcles cutrar, star $c$ axir $c$ de aquexc castillo e en la cambre do la dita Abbadesa stara, c faular coń clla toda hora que los scra bien visto. E aço no mudedes por alguna causa o raho..."

it $\Lambda$ C.A, $240+/ 12.3 \quad v-124$.

Zaragoz.a, 2 junio 1414.

"Don licrancio etc. A los amados e fiel nuestro Mossen Parcio lat Casta, Merino de la ciudat de faragoģa c Inhan de Hixar scudero tenientes el castille de Sora, salut c gracia: Como Xineno d'Odina, notario, cxibidor de la present de nucstra licencia $c$ mandamiento haia a fatular con la Abbadessa de Tresovares qui de present en el cito castillo es, mandamos ros expressament quel dito Ximeno lexedes franchament c quita cherar on el dito castillo c cxir d'aquell e faular con la dita $\Delta$ bladessa una e moltes vegades $e$ toda hora que a ell bien visto scra. E esto no mudecics por alguna causa o razon como nos assi fucramos sca fẹto. Dada en Caragoça, dius nuestro siello secreto a 11 dias de junio del anyo $M$ CCCC Xulli. Rex Ferdinanclus.-Dominus Rex mandarit mihi, Paulo Nicholai.-Provisum."

as $\Lambda C A, 2+04 ! 61$. 
Sorís al Papa, se expone toda la respuesta pontificia, llevada al rey por el mismo Suero Alfonso de Sorís, y resumida ch una larga consulta dirigidal a Francisco de Aramda. quizí la ligura juridica más destacada en aquellos momentos, consultor del Pontílice y del rey ".".

Del contenido de este memorial se deduce que, requericlo don Pedro de Urrea a entregar la abadesa, a requeri-miento del rey' y del Papa, después de las entrevistas soste.

$39 A C A, 2+(0+/ 130$, linca 17.

“... No resmenos por la dita creencia havemos sabido algun grcuge que Su Santedat ha preso solorel feyto de la Abbadessa. E puede Su Samtclat yumaginar que moln nuestro deseos es complir sus mandamienlos e ja. juxta aluellos nos requirimos a 1). Pedro Durrea mos liuras la dita Mblatelessal, el cual resjuso yue faria lo at que fuc's te-

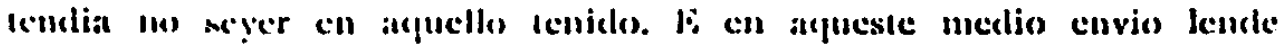

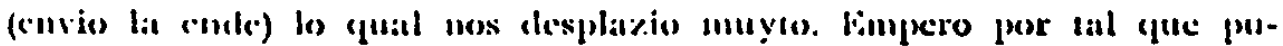

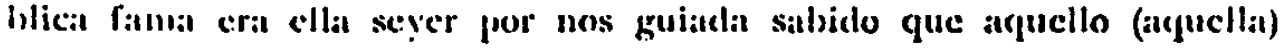
haviesscmos liurado a Su santedar harrya caydo en opinion de muyIus de mala intencion que no percebyan bien los motivos cncara que fuesien justos, rompiment e viobacion de nuestro guiatge e fe, la qual. oppinion c a nos cargosa c a los negocios de la Santa Unyon no poxo seria dimunosia; c cncara seria desscrvicio de Su Santedat; por todas acfucstas cosas Su santedat lo delxe tomar en paciencia e seral renido por lo millor. Car apres que la dita Abbadessa es stada con don Anthon de I.una, la qual sabredes vos como era condurescida cn su malicia c crror. Fil dito don Anthon al visjo de Cámorat qui de acpuesta matcria le havia scripto algunas cosis ha rescripto confessando su error e pecaclo e dezicuslo que quiere fazer toxdo lo yue nos. orclemaremos con tal condicion que ba dital Abbaclessa seal segura de vida, presion e mutilacion de micmbros. Io que por scripto dixo que mas largament enviarc. Porque es necessario quel dito Padre Santo. envic poeler al Bispo de fiamera de guiar la dita Abbadess, e salvarle vida, presion c mutilacion de micmbros; a sinarle que torne a su Monastcrio o en otro lugar do Su Santedat ordenara. li nos guiarcmos al dito Don Anthon que pueda venir a la tierra de Mossen Guillem Ramon de Mluncada. li semblenos millor que Su Sanctedat das qualque lugar del orde de Sent Johan de Cathalunya, que no fues casticllo. do cl dito Anthon stas con nostro guiagc, e con csto la Su Santedat havia las personas e las amimas pus cognosquen, segund clito. ss. su peceaclo e se tiren de aquells voluntariament..." 
nidas por clla en el castillo de Sorá con los citados prelados y notario --el obispo de Segovia, el confesor del rey y el notario Ximeno de Odino-, el citaclo don Pedro de Urrea "... repuse que faria lo que fues teniclo, c apres dio por scripto ciertas opposiciones por las cualcs pretendia no seyer en aquello tenido. E cn alquest medio envio1 ende " lo qual nos esplazio muyto...", o sea, que, aprovechando don Pedro de Urrea el cruce de las demandas y las respucstas, facilitó la tácita cvasión de la abadesa. lil rey creyó lo más prudente en el momento no perseguirla para entregarla al Pontífice, puesto que tenía guictjc real. y el entregarla habría levantado los ánimos. al parecer bastante excitados y pendientes del asunto de la abadesa. Mamilicsta sobre ello sus temores a Francisco de Aranda. diciéndole yne no sólo habría sido perjudicial a lat opinión sobre el rey. sino de recharo at los asuntos de la unión de la lglesia", pues, annque los motivos cran justos, muchos los habrían llevado a mala intención. imputando al rey "romplment e violacion de nuestro guiatge...". Se desprende de este documento que en su huida la abadesa se refugió en el mismo lugar donde se encontraba don Antón de Luna, y no fué en baldic. como se deduce de estas lineas. ya que parece ser fui el principio del arepentimiento de ambos: "... por todas aquestas cosas Su Santedat lo deve tomar en paciencia c sera veniclo por to millor. Car apres que la dita Abbadesa es starla con don Anthon de Luma, da qual sabredes ros como era endurescida en su malicia e crror. El dito Don Anthom al vispo de Çamora, que de aquesta materia le havia scripto algunas cosas. hat rescripto confessando su error e pecado e deziendo que quicre fazer todo lo que nos ordenaremos con ral condicion que la dita Abbadessa sea segura de vida, presion e mutilacion de miembres:

\footnotetext{
10 Contracción palcográfica cle "cnvio la ende".

11 Gestiones para la solución del Cisma, por ese motivo se preparaban las Vistas de Perpiñain.
} 
lo que por scripto dixo que mas largament enviave...". Ei obispo de Zamora necesitaba de Benedicto XIII la correspondiente autorización para guiar o absolver a la abadesa de tales penas en que habia incurrido por su pecido. Vistos estos destellos de arrepentimiento de ambos, el rey insinuia a Francisco de Aranda, que debe consultarlo y exponer todo el conteniclo de esta carta al Pontílice, insinúa. decimos, que se podría ordenar a la abadesa que volviese a su monasterio u a otro; y a Antón de Luna autorizarlo para entrar en tierra de Guillem Ramón de Moncada o mejor en algún lugar de los caballeros de San Juais de Jerusalén en Cataluña que no fuese castillo (o sea, plaza fuerte). Con ello Su Santidad “... havia las personas e las animas pus cognospuen segund dito es su peccado o se tiren de aquells voluntariament".

Unos tres meses debió durar la ausencia de la abadesa, ya que hasta septicmbre no encontramos noticia del asun10. Descle Morella 1" escribe el rey a su primogénito, que está en Zaragoza, para que intervenga con el gobernador de Aragón a fin cle que se cumpla el viaje que ha concedido a don Antón de Luna para que lleve la abadesa a Mequinenza y pueda separarse de ella ${ }^{43}$. Se cruza mucha correspondencia sobre la entrega y viaje de la abadesa, pues andaba dicha señora algo remisa en cumplir los de-

4 Mlorella, 10 septicmbre $1+14$.

4.3 AC:A, 2405;26.

"kil Rey:

Princep muy caro e muy amatio primogenito: Nos scrivimos al Governador d'Aragon tantost partat e se vinga a vos, c vos crehe delo que le diredes de nuestra part; por que por vigor de la dita crehenfal li explicaredes que nos por scrvicio de Dios e por tal que la Abbadessa de Tressoiares sea tiradia de pecado e torne a su Monasterio, o otro lugar onesto, e cxca de manos de Don Anthon de Luna, havemos guiado el dito bon Anthon que vinga a Miquinença con la dita Abbadessa. l'or tanto por los ditos sguarclos c por nuestra honor e scricio e dissimular li venida del clito Don Anthon provehiendo que ne por el ne gent suya nol fues a ell ne a los que lo acompanyaran entre los quales es en que nuestro algutziro aseyado ni feyto algun 
scos del rey y tal vez algo recelosa tambicin. Lin 24-IX-1414 ya ha cutrado en el reino ${ }^{4,}, y$, a últimos de octubre, mosen Juan de bardagi debe procurar por todos los medios acompanarta a Aycrbe $y$, si fuera posible vencer su resistcncia, que la acompañe hasta Mequincnza. Dura todo noviembre el forcejeo para lograr que se traslade la abadesa a Merquinenza, pero clla sc resiste en Ayerbe ${ }^{4.5}$. Por fin. el rey recibe unil carta fechada en Zaragoza el 12 de diciembre de $1+14$, de su escribimo de ración, que ha ido a dicha ciudiad por asuntos económicos, y en una signifrcativa postdatil escribe estas líncas: "Item Senyor so avisado por el Bayle Gencral que la Santa e buena Religiosa la Abadesal. quie se dize muller de don Anthon, es cn Ayerbe. que va por la villa con su fillo de la mano a su hell plazer. Nenticolo a la vuestra senorya por tal que si no lo sabiades que lo sepades en manera que provida-

clanyo ne depunatge. (ue en aquesto nos fara special scricio. E al contrario no dariamos alguna paciencia, cncargandolo sobre aquesto de ntestra part segunt la materia recuuicre. E haya vos, P'rincep muy caro e muy amado Primogenito, lo Sancto Spirito en suo continuo pro..muo c guarda. 1)ada en Moriella dius nuestro sicllo screto a $X$ clias cic Satiembre del anyo Mil CCCC XIIII. Rex Ferdinandus.Dominus Rex mandarit michi, Paulo Nicholai.-Provisum."

11 ACA, 240i/116(1).

Montblanch, 24 noviembre 1414.

"Nosicn Guillem Ramon: Segons harem cutes la Abbadessa es ja chtratla en lo Regne per venir aço del uni; per que us pregam e manam que vistes les presents, partiscats c vingats aci a nos per que a ros pugam praticar de ço que daci arant sia fahedor. $E$ aço no dilatets sins desitjats scrvir e complaurc. Dada en la vila de Muntblanch sots. nostre segell secret a XXIIII dies de Niovembre del ally in cocc: XIlll.--Rex ferdinandus.-Iohamis de Viterno. mandato regio. [ecit ad relacionem lauli Nicholai, Secretarii.-Provisum.-Al No ble e Amat Conscller nostre Mossen Guillem Ramon de Muntcada."

is Unas ocho cartas hemos cncontrado, durante los meses octubre-novicmbre $\mathrm{H}+\mathrm{H}$, sobre el traslado de la abadesa de Trasovares, dirigidas a Mn. Guillem Ramón de Moncada, a Mn. Antonio de Bardaxi, capitín de las montañas de Jaca, y a l'ero Pérez de Loraz, lu. gartenicnte de capitin de las montañas de Jaca. 
des en ella segunt vos sera bien visto" ${ }^{46}$. Recibida esta carta se terminan las contemplaciones y las consultas, las irclenes son yat definitivas y tajantes; se traslada la abadesa a Mepuincnzal, lugar de señorío de Guillém Ramón de Moncada, y se ordena a dicho señor, señor de Mequinenza, entreguc la abadesa a mosen Antoni Vicent, delegado por el Pontílice para recoger a la abadesa y llcvarla al lugar designado. Como duda el rey que doña Violante esté muy bien dispuesta a obedecer, hace responsable a. Guillém Ramón de Moncada, señor de Mequinenza, de hacer obedecer a la abadesa o de acompañarla él mismo a donde haya designado el Pontífice ". Esta orden es de 18 de enero de $1+15 \mathrm{y}$ con la misma fecha se extiende orden a la abadesa, que ni con la excusa de ir donde esté don Autón de Lmana, ni por otra alguma, puede moverse del lugar de Mequinen\%al ${ }^{\text {tx }}$. lil mes signiente, o seil con fecha 26 de febrero de $1+15$, se concede a Antón de Luma guicije de seguro - duradero cuarental días- de todos sus crímenes cometidos hasta el 1 de agosto de 1414, para el y cinco personas que lo acompañen. excluyendo de entre estas cinco personas a la abadesa. En este guiaje se le antoriza para parlamentar con el conde de Cardona y con Guillém Ramón de Moncada: puede estar en los lugares de Arbeca. Mequinenza, Juneda, Aytona y. Serón; no puede pasar al sur del bibro ni entrar en villas reales. $Y$ este guiaje sólo es valedero a condición de entregar la abadesa a lit autoridad pontilicia o a su legado, castigando con la pena de diez mil florines de oro de Aragón el incumplimiento de este guiaje y sus condiciones ${ }^{19}$.

Vemos que es el conde de Cardona el que debe partatmentar con Antón de Luma, y asimismo fuć el conde de Cardona, a quien fué enviado con toda urgencia don Iñigo López de Mendoza en el momento que se tuvo noticia

\footnotetext{
16 ACA, (.. R. 1).. caja 4, liernanclo I, muim. 542.

1i Valencia, 18 encro 1+15. ACA, 240.5/78 $\because$. (1.").

48 AC.A, $2+05 ; 78$ v. (2.").

4 AC. $1,2+05 / 121$.
} 
de la desiparicion de don sutón de lana. lodas estas coincidenciass en las misiones de nuestro maryues de Santillana. sus estancias documentadats en la corte aragonesil $\therefore$ y un viaje muy bien retribuído a Castilla realizado por el marcules también por este tiempo"s nos permiten suponer su interiención directa en todo el asunto: conocimiento del paradero de don Antón. comocimiento del lugar donde estaba presa la abadesa, su salida de Aragón al amparo del mismo don Pedro de Urrea -con sus dilaciones y correspondencia excusando entregarla-, y tal vez. llegó a saber también el marqués que la escapatoria se había hecho por un lugar poco vigilado de la frontera, como poría serlo el barranco de Morana. paso de los gamados de un reino a otro en las cpocas de pastorto ${ }^{32}$, y todo cllo to quiso condensar en una Serrmilla llena de encrgía y ambiente bastante lejanos ded idilin pastoril $y$ amoroso.

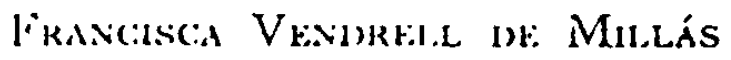

sil Sobre la estancia dicl marqueis de Santillana en la corte de Aragón, vid. nucstro cstuclio $y$ tesis doctoral La Corte Literaria de Alfonso $V$ de Arrgün, prigs. 64-70, Y nucstra celición del Cancionero de Palacio, pigs. 28 y sigs.

it liste viaje se le pagat con algunos días de postcrioridad.

5:2 El paso y marca de los gainados por el limite entre Aragón, Castilla y Navarra fuc motivo de muchos acuerdos y clisensiones y conferencias entre los tres reinos. 